\title{
WHEN TO INDICATE RADIOTHERAPY AFTER NIPPLE- SPARING MASTECTOMY? SYSTEMATIC REVIEW
} Quando indicar radioterapia após mastectomia nipple-sparing? Revisão sistemática

Fabiana Christina Araújo Pereira Lisboa*, Pollyanna Dornelas Pereira, Carlos Marino Cabral Calvano Filho, Thiago Machado Carlos de Carvalho', Cícero de Andrade Urban², Rivadávio Fernandes Batista de Amorim

\section{ABSTRACT}

Introduction: Nipple-sparing mastectomy (NSM) and preservation of the nipple-areola complex (NAC) represent a therapeutic option of breast cancer with a better aesthetic result, a positive impact on body image and more satisfaction than the reconstruction of the NAC. It is questioned the indication of radiotherapy when the NAC is maintained and its potential aesthetic impairment. Objective: To examine the indication of radiotherapy in NSM and, secondarily, the incidence of NAC involvement and local recurrence rates. Methods: Systematic review carried out in the PubMed database with the terms ("breast neoplasm" [Mesh] OR "breast cancer") AND ("radiotherapy" OR "radiation therapy") AND ("nipple sparing mastectomy" OR "mastectomies" OR "subcutaneous mastectomies"). The selection of the studies, the evaluation of its quality and data extraction were carried out independently by four reviewers. Results: The indications for radiotherapy after NSM were: positive axilla, tumors over $5 \mathrm{~cm}$ and retroareolar tissue remaining greater than $5 \mathrm{~mm}$. The NAC involvement occurred in 5 to $26.1 \%$ in the definitive anatomopathological study. NAC recurrence occurred from 2.59 to $10 \%$. NAC necrosis occurred in 2.2 to $43.4 \%$. Conclusions: The radiotherapy indications for NSM seem to follow the same classical indications for radiotherapy after mastectomy. The relapse index in NAC was not shown to be larger and without difference for the type of radiotherapy used. Radiotherapy should be based on factors that suggest a high risk for NAC involvement.

KEYWORDS: Breast cancer; radiotherapy; subcutaneous mastectomy.

\section{RESUMO}

Introdução: A mastectomia nipple-sparing (MNS) e a conservação do complexo aréolo-papilar (CAP) representam uma manobra terapêutica do câncer de mama com melhor resultado estético, impacto positivo na imagem corporal e mais satisfação do que a reconstrução do CAP. Questiona-se a indicação de radioterapia quando da manutenção do CAP e seu potencial prejuízo estético. Objetivo: Examinar a indicação de radioterapia em MNS e, secundariamente, a incidência do envolvimento do CAP e as taxas de recorrência local. Métodos: Revisão sistemática realizada na base de dados do PubMed com os termos ("breast neoplasm" [Mesh] OR "breast cancer") AND ("radiotherapy" OR "radiation therapy") AND ("nipple sparing mastectomy" OR "mastectomies" OR "subcutaneous mastectomies"). A seleção dos estudos, a avaliação da qualidade do estudo e a extração de dados foram realizadas de forma independente por quatro revisores. Resultados: As indicações para radioterapia após MNS foram: axila positiva, tumores acima de $5 \mathrm{~cm}$ e tecido retroareolar remanescente maior que $5 \mathrm{~mm}$. O envolvimento do CAP ocorreu em 5 a 26,1\% no anatomopatológico definitivo. A recorrência no CAP ocorreu de 2,59 a 10\%. A necrose do CAP ocorreu em 2,2 a 43,4\%. Conclusão: As indicações de radioterapia para MNS parecem seguir as mesmas indicações clássicas para radioterapia após mastectomia. O índice de recidiva no CAP não mostrou ser maior com uso de radioterapia nem ter diferença quanto ao seu tipo. A decisão de realizar a radioterapia deve se basear em fatores que sugerem alto risco para envolvimento do CAP.

PALAVRAS-CHAVE: Câncer de mama; radioterapia; mastectomia subcutânea.

${ }^{1}$ Universidade de Brasília - Brasília (DF), Brazil.

${ }^{2}$ Universidade Positivo - Curitiba (PR), Brazil.

*Corresponding author: fabianachristinalisboa@gmail.com

Conflict of interests: nothing to declare.

Received on: 12/13/2017. Accepted on: 06/24/2018 


\section{INTRODUCTION}

Nipple-sparing mastectomy (NSM) is a surgical technique for the preservation of the nipple-areola complex (NAC) and has become a possibility of mastectomy in the treatment of breast cancer and in risk-reducing surgery ${ }^{2}$. The aesthetic concern also arises in this new context, and this less invasive procedure protects the integrity of the NAC, whose removal may be considered an aggravating factor to the patient's mutilation feeling, as it is recognized as an attribute of femininity and identity of the breast, preserving their physical integrity ${ }^{3}$.

The conservation of the NAC brings better aesthetic result, positive impact on body image and more satisfaction than its reconstruction. However, there is concern about the risk of recurrence in NAC or the risk of a new primary breast cancer in the remaining breast tissue. This concern may have been based on initial descriptions of centripetal lymph drainage toward the subareolar plexus, as described by Sappey in $1885^{1}$.

It is questioned if the breast tissue, theoretically residual behind the NAC, should be treated with radiotherapy (RT) and what is the risk of local recurrence behind the NAC if the RT is not performed. In this scenario, it should be noted that studies are still limited to assess the role of RT in $\mathrm{NSM}^{1}$. Additional RT should play the same role as in conservative breast treatment, reducing the risk of local recurrence in the remaining breast tissue ${ }^{4}$. It should be considered that RT may bring with it considerable aesthetic impairment ${ }^{5}$. The studies do not clearly show the indications of RT when preserving NAC and what would be the best technique to be used.

The objective of this review was to evaluate the indication of RT in NSM and, secondarily, the incidence of NAC involvement and local recurrence rates.

\section{METHODS}

A systematic review of the literature was performed in the PubMed database with the following search strategy:("breast neoplasm" [Mesh] OR "breast cancer") AND ("radiotherapy" OR "radiation therapy") AND ("nipple sparing mastectomy" OR "mastectomies" OR "subcutaneous mastectomies") from April to June 2017, without restriction of publication date. Based on an initial research, the titles and abstracts found and the selection of the articles according to their eligibility and response criteria to the PICOS research question were followed, with $\mathrm{P}$ being the population (patients with breast cancer submitted to NSM; I the intervention (RT); $\mathrm{C}$ the comparison (no RT performing); $\mathrm{O}$ the outcomes (risk of local recurrence, involvement of the NAC and overall survival); and $\mathrm{S}$ the study/study design (randomized clinical trial and observational studies). This research was drafted in accordance with the PRISMAguidelines (Statement - Preffered Reporting Items for Systematic Reviews and Meta-Analyzes) ${ }^{6}$.

The inclusion criteria were: breast cancer patients submitted to NSM followed or not by RT, criteria for indication of RT, regardless of age and gender. Exclusion criteria were: pregnant women, inflammatory breast cancer, specific populations, locoregional metastasis and distance. The selection of the studies and the reading of the texts in their entirety were done independently by four reviewers and the articles that did not meet the eligibility criteria were excluded.

Regarding the extraction of the data of the selected articles, these were inserted in a spreadsheet of Microsoft Excel 2010, independently by four reviewers. The data selected were: author and year of publication, place of study, year of data collection, study design, sample size, age, gender, race/ethnicity, surgery indication, tumor size, location of the tumor, multicentricity, multifocality, positive axillary lymph nodes, criteria for RT indication, RT rate, follow-up, molecular classification, NAC involvement, NAC recurrence rate, NAC necrosis, histological subtype and association measure.

The quality of the studies was evaluated using the critical evaluation tools for studies of the Joanna Briggs Institute ${ }^{78}$. For cohort studies, the tool assesses, through 11 questions, items such as similarity between groups, exposure and outcome measures, strategies for confounding control, absence or non-outcome at the beginning of the follow-up of the participants, follow-up time, and statistic. For the case series, the tool evaluates ten questions about inclusion criteria, method, characteristics of participants, follow-up and statistical analysis. Each question may be answered with "yes","no", "uncertain" and "not applicable". The study with more "yes" answers is more likely to be of good quality, and, arbitrarily, those with scores between 0 and 3 are considered poor, between 3 and 6 are reasonable and those between 7 and 11 have good or high quality. The reviewers independently assessed the quality of each study. Disagreements were solved by consensus.

\section{RESULTS}

\section{Selection of studies}

A total of 223 articles were retrieved in the database search. After the screening of titles and abstracts, 19 full-text articles were read and evaluated for eligibility. In the end, 13 articles were considered for the systematic review due to their answering the research's question. Eligible studies were published between 2005 and 2017 and with collection period from 1980 to 2015. Figure 1 shows a flow diagram of the article selection process.

\section{Studies and characteristics of participants}

Four prospective cohorts ${ }^{2,3,9,10}$, two retrospective ones ${ }^{1,11}$ and seven case series ${ }^{4,5,12-16}$ were included, totaling 5,781 individuals. The studies collected had mean follow-up periods ranging from 13 months to 13 years. In most studies, women represented the largest proportion of the sample ${ }^{2,4,5,12-16}$. The mean age was 44 to 52 years ${ }^{10,16}$. Only one work ${ }^{1}$ mentions race/ethnicity, being $82 \%$ white, $42.9 \%$ black and $36.8 \%$ Asian. Table 1 shows the characteristics of the studies.

\section{Result definitions}

The tumor size considered was $\mathrm{T} 2^{1-3,5,10,14}$. The central location of the tumor was reported in 3 studies ${ }^{2,3,9}$, considering distances for 
$\mathrm{NAC}^{2}$ greater than $2.5 \mathrm{~cm}$ and at least $1 \mathrm{~cm}$ of the areola ${ }^{3,9}$ for its conservation. The indications for surgery were: multifocal, multicentric tumor, extensive intra-ductal carcinoma in situ (DCIS) ${ }^{15}$, bilateral cancer ${ }^{3}$, diffuse microcalcifications distant from NAC, negative intraoperative retroareolar freezing ${ }^{16}$ and prophylactic mastectomy ${ }^{2}$. Positive armpit was found in the frequency of 13 to $40.74 \%^{1-4,10,11,13-16}$. The indications for RT after NSM were: positive axilla, tumors ${ }^{1}$ over $5 \mathrm{~cm}$ and remaining retroareolar tissue ${ }^{2}$ greater than $5 \mathrm{~mm}$. Survival considered in the follow-up period was 100, $97^{1}$ and $76.4 \%$. NAC involvement occurred in 5 to $26.1 \%^{2,49,10,12,14-16}$ in the definitive anatomopathological study. Recurrence in the NAC occurred in 2.59 to $10 \%^{2,39,10,14-16}$. CAP necrosis occurred in

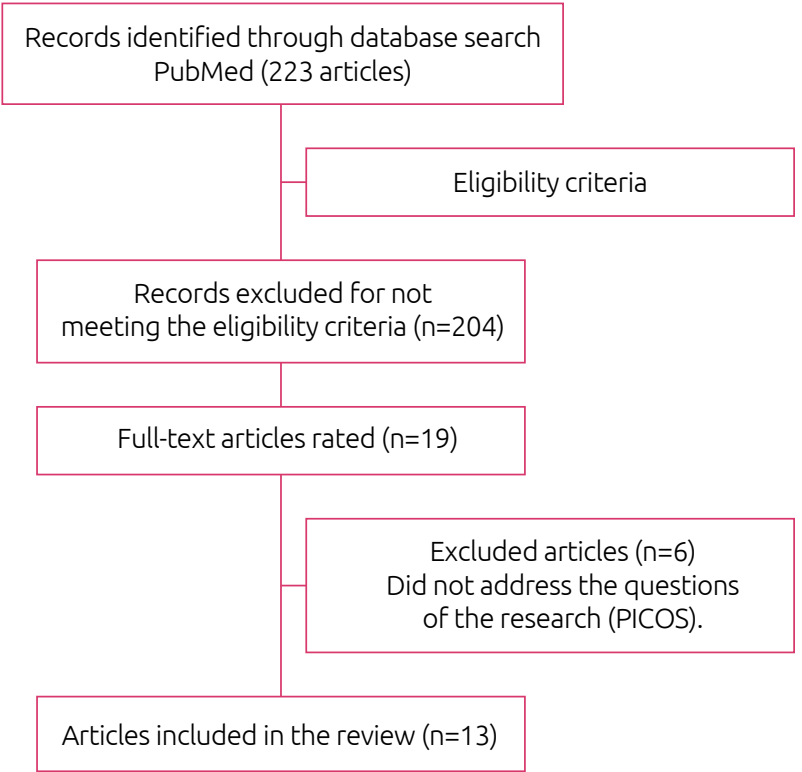

Figure 1. Flow diagram of the selection process.
2.2 to $43.4 \%^{2-5,9,12,16}$. The most frequent histological subtypes were infiltrating ductal carcinoma (IDC) and DCIS, with the following percentages: 56 to $82 \%^{1-3,9,10,16}$ and 9.26 to $40 \%^{1-3,9,10,16}$, respectively. The molecular classification represented 29 to $89.2 \%$ of positive estrogen receptor ${ }^{1,2,10,11,14,16}$, from 17.16 to $79.7 \%$ of HER-2 positive ${ }^{2,16}$ and $6.25 \%$ of triple negative ${ }^{13}$. The rate of RT in NAC was 16.6 to $100 \%^{1-3,9-11,13,15,16}$. The studies did not provide an association measure for overall and disease-free survival.

\section{Evaluation of the quality of the articles}

The case series showed scores, according to the JBI, averaging 7 to 8 "yes" answers for 6 rated articles and 6 for 1 article. The cohorts presented 6 studies with scores above 7 and 2 studies with scores 5 and 6 (because they did not adequately describe about follow-up and about how they dealt with confounding factors).

\section{DISCUSSION}

\section{Radiotherapy: indications and complications}

Because NSM is an approach that preserves the glandular tissue behind the areola to protect the vascularization of the NAC, postoperative RT could complement this treatment, reducing the risk of local recurrence. However, the use of radiation in patients submitted to NSM is variable in the literature ${ }^{9}$. In the present study, the rate of RT in NAC was from 16.6 to $100 \%$, showing a high variability of indication among the studies.

The indications for RT after NSM identified in the present review were positive axilla, tumors over $5 \mathrm{~cm}$ and retroareolar tissue remaining greater than $5 \mathrm{~mm}$. Such indications are similar to the general RT recommendations in breast cancer patients undergoing mastectomy and suggest that indications are for

Table 1. Characteristics of the studies.

\begin{tabular}{|c|c|c|c|c|c|}
\hline Author & Year & Period of data collection & Country & Sample size & Design of the study \\
\hline Agarwal et al. ${ }^{2}$ & 2014 & 2005 to 2009 & United States & 449 & Retrospective cohort \\
\hline Rulli et al. ${ }^{3}$ & 2013 & 2003 to 2011 & Italy & 77 & Prospective cohort \\
\hline Petit et al. ${ }^{4}$ & 2009 & 2002 to 2007 & Italy & 1,001 & Prospective cohort \\
\hline Reish $^{10}$ & 2015 & 2007 to 2012 & United States & 45 & Case series \\
\hline Petit et al. ${ }^{11}$ & 2009 & 2002 to 2007 & Italy & 579 & Case series \\
\hline Benediktsson e Perbeck ${ }^{13}$ & 2008 & 1988 to 1994 & Sweden & 216 & Prospective cohort \\
\hline Cont et al..$^{14}$ & 2017 & 2010 to 2015 & Italy & 518 & Case series \\
\hline Petit et al. ${ }^{16}$ & 2005 & 2002 to 2003 & Italy & 106 & Case series \\
\hline Agarwal e Argawal ${ }^{18}$ & 2015 & 2006 to 2010 & United States & 470 & Case series \\
\hline Petit et al. ${ }^{19}$ & 2005 & 2002 to 2005 & Italy & 333 & Prospective cohort \\
\hline Coopey et al. ${ }^{20}$ & 2013 & 2007 to 2013 & United States & 97 & Case series \\
\hline Cho et al. ${ }^{21}$ & 2015 & 2005 to 2014 & Korea & 85 & Case series \\
\hline Horiguchi ${ }^{22}$ & 2006 & 1980 to 2001 & Japan & 1,574 & Retrospective cohort \\
\hline
\end{tabular}


high risk patients, such as those with tumors larger than $5 \mathrm{~cm}$, positive axillary lymph nodes and positive margins. The results of recent trials on local RT extended these indications to intermediate risk patients (high risk with negative lymph nodes and 1 to 3 positive lymph nodes) $)^{9}$.

According to Marta et al. ${ }^{17}$, the opinions of radiotherapists and breast surgeons on the indications of RT for patients submitted to NSM and skin-sparing mastectomy were evaluated. Questionnaires with 22 questions were sent to radiotherapists and breast surgeons from North America, South America and Europe. A total of 550 physicians (298 radiotherapists and 252 breast surgeons), being $41.64 \%$ from South America, 29.45\% from North America and 25.82\% from Europe, answered the survey, and although they disagree on some aspects, with statistically significant differences, there was agreement that RT should be performed on early stage breast cancer (Iand II) for patients presenting risk factors for local recurrence. Although there is some disagreement among the interviewees, the standard risk factors for relapses considered important between the two specialties are: age under 40 years, involvement of 1 affected lymph node (radiotherapists) or 3 lymph nodes (breast surgeons), tumor greater than $5 \mathrm{~cm}$, extracapsular extension, compromised margins, lymphatic invasion, triple negative and multicentric tumors. Values between 1 and $5 \mathrm{~mm}$ were considered acceptable for residual mammary tissue. In cases of initial cancer (stage 0 to II), skin-sparing mastectomy is not associated with decreased systemic and locoregional control. This is not the case for more advanced tumors, which may reach $31 \%$ local recurrence compared to $5.8 \%$ in tumors with stage 0 to II. The most significant features for local recurrence are: lymph node involvement, tumor size, degree of tumor differentiation, and lymphovascular invasion ${ }^{17}$.

Thus, the indication of RT after NSM seems to follow the usual indications of RT after mastectomy and considers the associated risk factors, however, does not appear to be a consensus. This can be verified according to Agarwal and Agarwal, who evaluated in the literature whether patients submitted to NSM were more likely to receive RT. A total of 112,817 patients were submitted to NSM (470 patients, $0.4 \%$ ) and to other forms of mastectomy $(112,347 ; 99.6 \%)$ from 2006 to 2010. Patients submitted to NSM had higher RT rates than patients submitted to other forms of mastectomy in paired comparisons, taking axillary status and tumor size into account. RT was performed in $18 \%$ of patients submitted to NSM and did not meet the criteria established by the National Comprehensive Cancer Network (NCCN), compared to $6 \%$ in the group of other types of mastectomy ${ }^{18}$. This behavior of a certain tendency to indicate RT simply because of the maintenance of the NAC still needs to be reviewed and a consensus must be established in international protocols regarding the standard conduct in these cases.

Some discussion points related to post-NSMRT refer to the local complications associated with it: NAC necrosis, capsular contracture and deviation of the NAC position influence the final aesthetic result of the reconstructions. In a retrospective study, Reish et al. evaluated 605 immediate breast reconstructions made after NSM. Of these, 88 were treated with RT. There was a trend towards more complications in patients submitted to RT (19.3 versus $12.8 \% ; \mathrm{p}=0.099$ ) associated with a higher risk of implant loss ( 6.8 versus $1.0 \%$; $\mathrm{p}=0.001$ ). Preoperative RT had a higher risk of total complications - with $\mathrm{p}=0.04$; odds ratio (OR) 2.225; and 95\% confidence interval (95\%CI), 1.040-4.758) - , and postoperative RT had a higher risk of extrusion $(\mathrm{p}=0.015, \mathrm{OR}=5.634,95 \% \mathrm{CI}, 1.405-22.603)$. There was no significant difference in the need for NAC removal due to poor positioning or positive cancer margins in irradiated patients compared to non-irradiated patients. The irradiated patients had a higher incidence of secondary procedures due to capsular contracture (12.5 versus $2.3 \%$; $\mathrm{p}<0.001)$ and steatonecrosis $(13.6$ versus $3.9 \%$; $<<0.001)$. The total success rate for NAC preservation was $90 \%$ (79 out of 88 ) and the rate of reconstruction failure was $8 \%{ }^{10}$.

The results of another study, a meta-analysis by Zheng et al., Indicate that the rate of occurrence of NAC necrosis and local recurrence is the same among patients who received and the ones did not receive RT, however, cutaneous necrosis is more common in irradiated patients ${ }^{15}$. Such possible complications should begin to be taken into account, since there currently seems to be more flexibility to indicate RT when NSM is performed, even in situations where it would not radiate if the NAC had been removed.

\section{Involvement of the areola-papillary complex}

Gomez et al. reviewed NSM publications focusing on the incidence of NAC involvement in post-surgery recurrence rates and on post-NSM RT data. The reported rate of NAC involvement ranged from 0 to $58 \%$. The factors most commonly associated with NAC involvement were: clinical suspicion of NAC involvement, tumor distance to CAP $(<2 \mathrm{~cm})$, tumor size $(>2 \mathrm{~cm})$, location of the primary tumor in the central quadrant of the breast, multicentricity/multifocality and axillary lymph node involvement $^{1}$. In the present study, the NAC involvement rate was 5 to $26.1 \%$ in the definitive anatomopathological study.

Agresti et al. evaluated 422 patients submitted to NSM, of whom 61 were referred to neoadjuvant chemotherapy (QT-neo). The compromised NAC, seen during intraoperative and/or in the histological final freezing, in the NSM group and the NSM-post chemotherapy was seen, respectively, in 48 of 361 cases (13.3\%) and in 6 of 61 cases (9.8\%). Of the 54 patients with NAC commitment, 51 were submitted to resection of the NAC and 3 to the RT, according to the patient's desire to preserve the NAC. The three patients did not present local recurrence. Of the 51 patients who underwent NAC removal, residual disease was found in 21 of them (5 IDC and 16 DCIS), with no significant difference between those who underwent QT-neo and those who did not ${ }^{12}$. Benediktsson et al., in a series of 272 patients submitted to NSM and retroareolar freezing, observed that the sensitivity of freezing was $90.9 \%$ and the specificity was $98.5 \%$ in the assessment of retroareolar 
involvement by the disease ${ }^{13}$. Intraoperative freezing seems to be a safe method for deciding whether or not to preserve the NAC according to the data evaluated.

\section{Local recurrence after nipple-sparing mastectomy}

In addition to total or partial necrosis of NAC and loss of sensitivity, local recurrence is one of the major concerns when thinking about NSM. In the series of 272 patients submitted to NSM evaluated by Benediktsson et al., only 47 received RT. Among the irradiated patients, the locoregional recurrence rate (LRR) was $8.5 \%$ after 13 years. In that study, the occurrence of LRR after NSM was independent of staging and lymph node status and did not affect overall survival. Late LRR (after three years) had a better prognosis than the initial ones. The frequency of LRR, according to the authors, can be substantially reduced by $\mathrm{RT}^{13}$.

The study by Petit et al. concluded that the local recurrence rate in NSM with RT was not higher than that observed in the literature after conventional mastectomies and the preservation of NAC would not increase this risk ${ }^{16}$. In a series of 137 cases evaluated, the patients underwent intraoperative RT (intraoperative single electron dose radiotherapy - ELIOT) and the NAC was preserved even when the freezing of the retroareolar tissue was positive. Two local recurrences (1.5\%) were observed, both located at least $2 \mathrm{~cm}$ away from the areola. One of the patients who had recurrence had a positive DCIS retroareolar histology, however, there was no recurrence in NAC in 18 patients with persistent positive histology ${ }^{19}$. NAC recurrence occurred in 2.59 to $10 \%$ in the present review and literature data show a relatively small relapse rate, which may suggest oncological safety in the indication of NSM in low risk patients.

Cont et al., in a series with 518 patients, observed that recurrences after NSM almost invariably occurred in the subdermal tissue of the flap that covered the tumor area rather than the NAC. In this series, the high degree and the high rate of tumor proliferation, both in invasive and in situ tumors, were significantly associated with local recurrence, whereas no recurrence occurred in cases submitted to RT. Thus, according to the authors, it is assumed that in selected patients submitted to NSM, the partial RT of the thoracic wall directed to the primary tumor's quadrant may be associated with the same reduction of recurrences as the RT of the whole breast, reducing thus complications in reconstruction ${ }^{14}$. Similar results were found by Petit et al. in a series of 579 patients, in which they found a recurrence rate of $0.9 \%$ per year, with the majority of recurrences occurring in the tumor site and not in the $\mathrm{NAC}^{11}$. Thus, the NAC should not always be the target of adjuvant RT.

Rulli et al. prospectively evaluated 77 patients who underwent NAC sparing mastectomy between 2003 and 2011. Patients aged between 18 and 75 years, those with a diagnosis of DCIS or IDC with a size smaller than $2.5 \mathrm{~cm}$, with distance from the tumor with CAP greater than $2.5 \mathrm{~cm}$, with lesion not located in the central quadrant of the breast, without bloody papillary discharge, without cutaneous involvement, with indication of mastectomy due to multifocal disease or diffuse microcalcifications and negative intraoperative histological evaluation of the retroareolar region. Patients with inflammatory carcinoma, those submitted to QT-neo, and those with Paget's carcinoma were excluded. During the follow-up of these patients (mean of 55 months), 2 locoregional recurrences were observed in $\mathrm{NAC}$, which were treated with surgical removal of the NAC at 33 and 37 months of follow-up ${ }^{3}$. The safety of the NSM is also supported by the distance of the tumor to the NAC and the distance limit of $2.5 \mathrm{~cm}$ seems to be indicated for the oncological safety of NAC preservation.

Petit et al. described the results of 1,001 patients submitted to NSM, and 800 received the ELIOT technique of intraoperative RT of NAC and 201 received late RT. The mean follow-up of 20 months showed $3.5 \%$ total NAC necrosis, $5.5 \%$ partial necrosis, and $5 \%$ of the cases required surgical removal. There were $2 \%$ of infections and $4.3 \%$ of the prostheses were removed. Partial sensitivity of preserved NAC was reported by $15 \%$ of patients. Of the 14 cases of recurrence (1.4\%), 10 occurred in an area near the site of the primary tumor, all distant from the irradiated NAC. There was no recurrence in the NAC. There were, in general, 36 cases of metastatic diseases with four deaths. The fact that there was no recurrence in NAC is a strong argument in favor of the efficacy of RT in NAC even with a short follow-up of patients ${ }^{4}$, however, one should wait for the result of a longer follow-up and that a randomized and prospective study comparing NSM with or without $\mathrm{RT}$ in the NAC is performed, since other works that did not perform RT also have low recurrence rates in the CAP at follow-up.

\section{Limitations and strengths of the present study} The evaluation of the quality of articles according toJBI showed that the case series appeared to be of good to high quality, with an average of 7 to 8 "yes" answers for 6 articles evaluated and 6 for 1 article of reasonable quality. Cohorts presented good and high quality for 6 studies with scores above 7 and reasonable quality for 2 studies with scores 5 and 6 . This result indicates that the studies included in this review have a low risk of bias and have adequate data reliability, according to critical evaluation items, with most of them identifying confounding factors and appropriate statistical analysis.

It was not possible to perform a meta-analysis on RT in NAC after NSM, local recurrence after NSM and global and disease-free survival due to different study models between selected articles and lack of adequate association measure.

\section{CONCLUSION}

NSM, after negative retroarticular freezing and following the appropriate indication criteria, appears to be oncologically safe in the treatment of breast cancer, as long as the tumor is not close to the CAP and the retroareolar tissue has adequate thickness. Intraoperative freezing is a safe method of deciding whether or not the NAC should be preserved. 
The indications of RT for NSM appear to follow the same classical indications for RT after mastectomy and the rate of relapse in NAC has not been shown to be larger with or without RT and no difference for the type of RT used. Only the achievement of NSM is an inadequate justification for RT post-mastectomy. The decision to perform RT should be based on preoperative imaging, clinical factors or pathological findings that suggest a high risk for NAC involvement. Although adjuvant RT is not an absolute contraindication in NSM, it should be used with caution as it decreases the final cosmetic result.

Prospective studies should be performed to adequately assess local recurrence rates in NAC after NSM with or without RT.

\section{REFERENCES}

1. Gomez C, Shah C, McCloskey S, Foster N, Vicini F. The Role of Radiation Therapy after Nipple-Sparing Mastectomy. Ann Surg Oncol. 2014;21:2237-44. https://doi.org/10.1245/s10434-013-3446-z

2. Agarwal S, Agarwal S, Neumayer L, Agarwal JP. Therapeutic nipple-sparing mastectomy: trends based on a national cancer database. Am J Surg. 2014;208;93-8. https://doi.org/10.1016/j. amjsurg.2013.09.030

3. Rulli A, Caracappa D, Barberini F, Boselli C, Cirocchi R, Castellani E, et al. Oncologic Reliability of Nipple-sparing Mastectomy for Selected Patients with Breast Cancer. In Vivo. 2013;27:387-94.

4. Petit JY, Veronesi U, Orecchia R, Rey P, Martella S, Didier F, et al. Nipple sparing mastectomy with nipple areola intraoperative radiotherapy: one thousand and one cases of a five years experience at the European institute of oncology of Milan (EIO). Breast Cancer Res Treat. 2009;117:333-8. https:// doi.org/10.1007/s10549-008-0304-y

5. Boyero MR.La mastectomia ahorradora de piel como alternativa a la mastectomia estándar em el cáncer de mama. Cir Esp. 2008;84(4):181-7. https://doi.org/10.1016/S0009-739X(08)72617-4

6. Moher D, Liberati A, Tetzlaff J, Altman DG, PRISMA Group. Preferred Reporting Items for Systematic Reviews and MetaAnalyses: The PRISMA Statement. PLoS Med. 2009;6(7):1-6. https://doi.org/10.1371/journal.pmed.1000097

7. Joanna Briggs Institute. Critical Appraisal Checklist for Cohort Studies [Internet]. Austrália: Joanna Briggs Institute; 2016 [acesso em: 10 out. 2017]. Disponível em: http://joannabriggs. org/research/critical-appraisal-tools.html

8. Joanna Briggs Institute. JBI Critical Appraisal Checklist for Case Series [Internet]. Austrália: Joanna Briggs Institute; 2016 [acesso em: 10 out. 2017]. Disponível em: http://joannabriggs. org/research/critical-appraisal-tools.html

9. Orecchia R. The use of postoperative radiation after nipple sparing mastectomy. Orecchia. Gland Surg. 2016;5(1):63-8. https://dx.doi.org/10.3978\%2Fj.issn.2227-684X.2015.11.01

10. Reish RG, Lin A, Phillips NA, Winograd J, Liao EC, Cetrulo CL Jr., et al. Breast Reconstruction Outcomes after Nipple-Sparing Mastectomy and Radiation Therapy. Plast Reconstr Surg. 2015;135:959-66. https://doi.org/10.1097/PRS.0000000000001129

11. PetitJY, Veronesi U, Rey P, Rotmensz N, Botteri E, Rietjens M, et al. Nipple-sparing mastectomy: risk of nipple-areolar recurrences in a series of 579 cases. Breast Cancer Res Treat. 2009 Mar;114(1):97101. https://doi.org/10.1007/s10549-008-9968-6

12. Agresti R, Sandri M, Gennaro M, Bianchi G, Maugeri I, Rampa M, et al. Evaluation of Local Oncologic Safety in Nipple Areola
Complex-sparing Mastectomy After Primary Chemotherapy: A Propensity Score-matched Study Cancer. Clin Breast Cancer. 2017;17(3):219-31. https://doi.org/10.1016/j.clbc.2016.12.003

13. Benediktsson KP, Perbeck L. Survival in breast cancer after nipple-sparing subcutaneous mastectomy and immediate reconstruction with implants: a prospective trial with 13 years median follow-up in 216 patients. Eur J Surg Oncol. 2008 Feb;34(2):143-8. https://doi.org/10.1016/j.ejso.2007.06.010

14. Cont NT, Maggiorotto F, Martincich L, Rivolin A, Kubatzki F, Sgandurra $\mathrm{P}$, et al. Primary tumor location predicts the site of local relapse after nipple-areola complex (NAC) sparing mastectomy. Breast Cancer Res Treat. 2017;165:85-95. https:// doi.org/10.1007/s10549-017-4312-7

15. Zheng, Zhong M, Ni C, Yuan H, ZhangJ. Radiotherapy and nippleareolar complex necrosis after nipple-sparing mastectomy: a systematic review and meta-analysis. Yajuan Radiol Med. 2016;122:171-8. https://doi.org/10.1007/s11547-016-0702-x

16. Petit JY, Veronesi U, Orecchia R, Luini A, Rey P, Intra M, et al. Nipple-sparing mastectomy in association with intra operative radiotherapy (ELIOT): A new type of mastectomy for breast cancer treatment. Breast Cancer Res Treat. 2006 Mar;96(1):4751. https://doi.org/10.1007/s10549-005-9033-7

17. Marta GN, Poortmans P, Barros AC, Filassi JR, Freitas Junior R, Audisio RA, et al. Multidisciplinary international survey of post-operative radiation therapy practices after nipplesparing or skin-sparing mastectomy. Eur J Surg Oncol. 2017 Sep 19;43:2036-43. https://doi.org/10.1016/j.ejso.2017.09.014

18. Agarwal S, Agarwal J. Radiation Delivery in Patients Undergoing Therapeutic Nipple-Sparing Mastectomy. Ann Surg Oncol. 2015;22:46-51. https://doi.org/10.1245/s10434-014-3932-y

19. Petit JY, Veronesi U, Luini A, Orecchia R, Rey PC, Martella $\mathrm{S}$, et al. When mastectomy becomes inevitable: the nipplesparing approach. The Breast. 2005 Dez;14(6):527-31. https:// doi.org/10.1016/j.breast.2005.08.028

20. Coopey SB, Tang R, Lei L, Freer PE, Kansal K, Colwell AS, et al. Increasing eligibility for nipple-sparing mastectomy. Ann Surg Oncol. 2013 Oct;20(10):3218-22. https://doi.org/10.1245/ s10434-013-3152-x

21. Cho JW, Yoon ES, You HJ, Hyon-Surk Kim HS, Lee BI, Park SH. Nipple-areola complex necrosis after nipple sparing mastectomy with immediate autologous breast reconstruction. Arch Plast Surg. 2015 Sep;42(5):601-7. https://doi.org/10.5999/aps.2015.42.5.601

22. HoriguchiJ, KoibuchiY,Yoshida T, Takata D, Kikuchi M, Rokutanda $\mathrm{N}$, et al. Significance of local recurrence as a prognostic factor in the treatment of breast cancer. Anticancer Res. 2006;26:569-74. 